\title{
Determining hydraulic characteristics in laterals and drip irrigation systems
}

\author{
Diego Chamba*, Sergio Zubelzu, Luis Juana \\ Departamento de Ingeniería Agroforestal, Universidad Politécnica de Madrid. Av. Complutense s/n, 28040, Madrid, Spain
}

\section{A R T I C L E I N F O}

\section{Keywords:}

Drip irrigation

Evaluation

Hydraulic characterisation

Emitter discharge

Head loss

\begin{abstract}
A B S T R A C T
Evaluation methods for functioning drip irrigation units are proposed to determine the hydraulic characteristics of emitters and pipelines. The aim of the study was to characterize the discharge curve of the emitters, their coefficient of variation, and the head losses in laterals and submains. In the laboratory, four laterals were tested under a wider range of pressure heads than the typical values of field installations. In additional, a field irrigation unit was evaluated. The discharge curve and coefficient of variation were determined in the unit with an accuracy similar to that obtained from laboratory experiments. For self-compensating emitters, a constant flow rate above the lower limit of the compensating range and an orifice-type discharge curve below that limit are proposed. For non-compensating emitters, an orifice-type discharge curve, with exponent $x=0.5$, except for specific cases, is proposed. The manufacturing coefficient of variation was independent of pressure and relatively low for all the analysed emitters. Regarding the parameters of the local head losses, the equivalent length le presented values more independent of the flow than coefficient $K$. For the characterisation of laterals with selfcompensating emitters, it is recommended to measure with the downstream end open to reduce the uncertainty in the experiments. The results show that the unit can be operated so that the average discharged flow and the uniformity can be matched just controlling the pressure head at upstream end point of the unit.
\end{abstract}

\section{Introduction and objectives}

In the bulk of cases, drip irrigation units are subjected to extreme environments; this results in variation of their hydraulic characteristics with time. Experiments to determine emitter discharge curves and lateral evaluations are frequently conducted under laboratory conditions that differ from real field conditions. Therefore, the field operating conditions of the bulk of the drip irrigation units can differ from those considered at the design stage or measured in the laboratory. Most of the operating decisions, for example the inlet pressure head or flow or the irrigation depth, are defined from a number of metrics obtained from the evaluation, such as the manufacturing coefficient of variation that determines the distribution uniformity (Chamba et al., 2019). Therefore, accurate knowledge of the actual operating conditions requires conducting field experiments in which the emitter discharge curve could be determined, or the unit evaluated.

With regards to the evaluation methods, Merriam and Keller (1978) reported a widely used field evaluation method that, with minor modifications, was adapted by the Food and Agriculture Organization (FAO, 1986). This method requires selecting four laterals located at $x=$ $0, L / 3,2 L / 3$, and $L \mathrm{~m}$, with $L$ the submain length. In each lateral, four measurement points (two emitters at each one for averaging) are selected at $y=0, L_{t} / 3,2 L_{t} / 3$, and $L_{t} \mathrm{~m}$, with $L_{t}$ the lateral length. The discharged flows of each emitter under different pressure head values are measured. The procedure is simple and practical for its primary objective, however, from a theoretical point of view, in order to adequately represent the distribution of water in the unit, these locations are not the most adequate and the average is not representative if the two drippers do not water the same plant (Juana et al., 2007). Bralts and Kesner (1983), with subsequent modifications of Bralts and Edwards (1986) and Bralts et al. (1987) collected in American Society of Agricultural and Biological Engineers (1998), presented a statistical approach by selecting 18 random locations. Although identifying the points randomly has positive aspects, it is not reasonable to neglect previous knowledge of hydraulic behaviour of drip irrigation units, which can be used, with the same amount of effort, to improve the evaluation quality.

Therefore, Juana et al. (2007) proposed selecting the measurement points to achieve the maximum representativity in terms of average pressure and variance for the entire unit. These authors recommended measuring at 16 locations, with two emitters at each one but, unlike Merriam and Keller (1978), not for averaging but for determining the manufacturing coefficient of variation. Juana et al. (2007) proposed, for the hydraulic characterisation, the pressure measurement at the

\footnotetext{
* Corresponding author.

E-mail addresses: diego.chambaz@alumnos.upm.es (D. Chamba), sergio.zubelzu@upm.es (S. Zubelzu), luis.juana@upm.es (L. Juana).
} 


\begin{tabular}{|c|c|c|}
\hline \multicolumn{2}{|c|}{ Nomenclature } & $L_{a}$ \\
\hline$C V_{m}$ & manufacturing coefficient of variation & le \\
\hline$D$ & internal diameter section $[\mathrm{L}]$ & $l e_{a r}$ \\
\hline$D_{n}$ & nominal diameter $[\mathrm{L}]$ & $m$ \\
\hline$e$ & pipe thickness [L] & $\mathrm{N}$ \\
\hline$e_{r Q}$ & relative error of the inlet flow rate & $q$ \\
\hline \multicolumn{2}{|c|}{$f(x / L, y / L t)$ fraction of the distance from the submain and lateral } & $Q$ \\
\hline$F$ & distribution probability function (aggregated probability) & $Q_{0}$ \\
\hline$g$ & gravitational acceleration $\left[\mathrm{LT}^{-2}\right]$ & \\
\hline$H$ & energy & \\
\hline$h$ & pressure head [L] & \\
\hline$H_{O}$ & inlet head at the submain and the lateral $[\mathrm{L}]$ & \\
\hline$h_{0}$ & inlet pressure head $[\mathrm{L}]$ & $q_{i}$ \\
\hline$h_{a v}$ & average pressure head $[\mathrm{L}]$ & $q_{\text {ies }}$ \\
\hline$h f$ & head loss [L] & $Q_{L}$ \\
\hline$h f_{r}$ & lateral head loss [L] & $q_{n}$ \\
\hline$h f_{t}$ & submain head loss $[\mathrm{L}]$ & \\
\hline$h_{\text {iest }}$ & estimated pressure head & $\mathrm{R}^{2}$ \\
\hline$H_{L}$ & head pressure at downstream end $[\mathrm{L}]$ & $r_{L}$ \\
\hline$h_{L}$ & $\begin{array}{l}\text { pressure head at the downstream end of the submain and } \\
\text { the lateral }[\mathrm{L}]\end{array}$ & $s$ \\
\hline$h_{\min }$ & minimum pressure head $[\mathrm{L}]$ & $x$ \\
\hline$I$ & hydraulic gradient & $z$ \\
\hline K & friction coefficient at emitter of the local loss parameter & $v$ \\
\hline$k$ & coefficient in the emitter discharge equation $\left[\mathrm{L}^{3-\mathrm{x}} \mathrm{T}^{-1}\right]$ & $\sigma$ \\
\hline$L$ & length $[\mathrm{L}]$ & \\
\hline
\end{tabular}

\author{
accumulated length [L] \\ lateral's length [L] \\ equivalent length of the local loss parameter [L] \\ equivalent length at insertions of laterals [L] \\ flow exponent in empirical expression of head loss \\ amount of data \\ emitter discharge $\left[\mathrm{L}^{3} \mathrm{~T}^{-1}\right]$ \\ flow discharge $\left[\mathrm{L}^{3} \mathrm{~T}^{-1}\right]$ \\ inlet flow $\left[\mathrm{L}^{3} \mathrm{~T}^{-1}\right]$ \\ discharged flow of the low quarter $\left[\mathrm{L}^{3} \mathrm{~T}^{-1}\right]$ \\ average discharge $\left[\mathrm{L}^{3} \mathrm{~T}^{-1}\right]$ \\ expected emitter discharge flow applying its characteristic \\ equation $\left[\mathrm{L}^{3} \mathrm{~T}^{-1}\right]$ \\ measured discharge $\left[\mathrm{L}^{3} \mathrm{~T}^{-1}\right]$ \\ estimated discharge $\left[\mathrm{L}^{3} \mathrm{~T}^{-1}\right]$ \\ outlet flow at downstream end $\left[\mathrm{L}^{3} \mathrm{~T}^{-1}\right]$ \\ emitter nominal discharge $\left[\mathrm{L}^{3} \mathrm{~T}^{-1}\right]$ \\ flow rate applied per each irrigation $\left[\mathrm{L}^{3} \mathrm{~T}^{-1}\right]$ \\ coefficient of determination \\ quotient between the incoming and the outcoming lateral \\ flows \\ emitter spacing $[\mathrm{L}]$ \\ emitter exponent \\ elevation level [L] \\ kinematic water viscosity $\left[\mathrm{L}^{2} \mathrm{~T}^{-1}\right]$ \\ Standard deviation
}

ends of the unit and a procedure based on simplified analytical expressions for trapezoidal units with uniform slopes. This study builds on this proposal.

Otherwise, and concerning the determination of the discharge curve, the standardised tests (see, for example, ISO, 2004) propose using flow values frequently smaller than the typical values of the field units. Therefore, if the emitter entrance is not aerodynamic, in a number of emitters, flow separation can occur, which decreases the pressure in the emitter water inlet (as shown in Fig. 1). This can result in a lower discharge flow rate in non-compensating emitters or an incorrect determination of the compensation range in compensating emitters. The greater flow that typically flows in the units can generate greater turbulence in the separation zone and, as a result, produce more pressure oscillations, which could affect both the flow rate and the manufacturing coefficient of variation of the emitters. In this case, the lateral tests would better reproduce the actual operating conditions than the standardised tests.

Concerning the local head losses, testing laterals with different lengths, with similar flow rates, could also condition differences in the flow separation. The flow rate conditions result in different flow contraction conditions, which would imply an overestimation or underestimation of the local head losses. Although the effect is mostly not critical, it can be accentuated in the case of sealed drippers, as specified for tests in accordance with the American standard ANSI-ASAE S553, (ASAE, 1998). The water outlet can decrease the separation and, therefore, decrease local head losses. Some evidence of those phenomena was reported by Lorenzo and Juana (2010) and Benítez and Juana (2012), who described the effect as insignificant.

In this context, to accurately characterise the entire unit, both the laterals and the submain must be studied. Although the characterisation of the laterals and emitters is conducive to standardisation, the analysis of submains presents a number of problems. There can be as many different submains installed as units and, on occasions, the lateral insertions are buried, therefore, obtaining actual measurements at these points is not easy. However, the submain hydraulic behaviour could be simulated without losing reliability using certain measurements at, for example, the upstream and downstream submain end points.

Therefore, the primary objective of this study was to evaluate procedures that allow the hydraulic characterisation of the behaviour of emitters, laterals, and submains in drip irrigation units in the field, as well as assessing their accuracy and applicability. The following specific objectives were proposed: (1) to determine the discharge curve and the manufacturing coefficient of variation in laterals trials to compare them to those obtained with the ISO standardised tests, (2) to determine and characterise in the laboratory the total head losses and the local losses for laterals using both the equivalent length $l e$ and the coefficient $K$ that multiplies the kinematic term, (3) to define and verify evaluation methods in the field to estimate the pressure head distribution, the discharged flows, and the parameters of both the emitters discharge equations and the head losses, and (4) to propose operation strategies for the unit in terms of operating pressure head.

\section{Material and methods}

\subsection{Laboratory experimental runs}

\subsubsection{Emitters characterisation}

Four models of drip pipe were analysed. Table 1 presents the hydraulic characteristics provided by each manufacturer.

A sample of 24 emitters of each pipe were tested following the standardised procedure established in ISO (2004). A dripper test bench (Fig. 2) was used for the standardised tests. In this bench a pumping group boosts the water into four smashed stretches.

Each drip pipe was tested in the bench at different pressure head values: ten trials increasing the pressure from 1 to $25 \mathrm{~m}$, and other ten
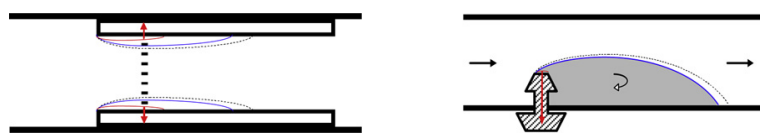

Fig. 1. Separation of the flow caused by the presence of the emitter; the water outlet can reduce the separation. 
Table 1

Hydraulic characteristics of the analysed drip pipe models.

\begin{tabular}{cccccccc}
\hline Model & $D_{n m}(\mathrm{~mm})$ & $e(\mathrm{~mm})$ & $s(\mathrm{~m})$ & $q_{n}(\mathrm{~L} / \mathrm{h})$ & $x$ & $\begin{array}{l}\text { Pressure } \\
\text { compensating }\end{array}$ & $\begin{array}{l}\text { Range } \\
\text { (bar) }\end{array}$ \\
\hline A & 16 & 1 & 0.75 & 2.3 & 0 & Yes & $0.5-4$ \\
B & 16.2 & 1 & 0.6 & 1.6 & 0 & Yes & $0.4-3$ \\
C & 16 & 0.9 & 0.75 & 2.15 & 0.49 & No & \\
D & 16.2 & 1 & 0.3 & 1.5 & 0.46 & No & \\
\hline
\end{tabular}

Note: $D_{n}$ : nominal diameter; $e$ : pipe thickness; $s$ : emitter spacing; $q_{n}$ : emitter discharge; $x$ : emitter exponent.

trials decreasing from 25 to $1 \mathrm{~m}$.

\subsubsection{Experimental procedure in drip laterals}

A $100 \mathrm{~m}$ length of each type of pipe presented in Table 1 was tested. For these experiments, a pump equipped with frequency converter was used to set the pressure and flow conditions.

The scheme of the experimental installation is presented in Fig. 3.

The incoming flow was measured with a digital flow meter (model CZ 2000-3 M, 1 inch). The flow at the downstream end was measured, if applicable, with analogue flowmeters (model M150, 1/2 inch). In both cases the flow was measured for between 1 and $2 \mathrm{~min}$. The flowmeters were checked against each other and with volumetric measurements.

Both the upstream and the downstream end pressure heads, and the difference between them (representing the head losses), were measured with digital manometers (models 2083P and 2082P, precision \pm $0.15 \%)$. To estimate the manufacturing coefficient of variation, the discharged flow at 25 emitters (in groups of five consecutive emitters located at $f=x / L=0.084,0.313,0.5,0.687$, and 0.916 , as reported by Juana et al. (2007) was also measured.

With emitter A, 45 experimental runs were conducted (28 with the pressure head inside the self-compensating range). With emitter $\mathrm{B}, 38$ experimental runs were conducted (32 with the pressure head within inside self-compensating range).

In addition, with the downstream end open, 10 supplementary experiments were conducted with emitter A and seven with emitter B. To calculate $C V_{m}$, the flow rates of 25 emitters were measured in five experiments with the downstream end closed, and in two experiments with the downstream end open with emitter A. For emitter B, the flow rates of 25 emitters were also measured in two experiments.
For non-compensating emitters, 60 experimental runs were conducted (in two batches of 30 runs each) with emitter C and 43 with emitter D (36 in the first batch and 7 in the second batch). The flow of 25 emitters was measured for determining $C V_{m}$ with 4 experimental runs with the emitter $C$, and 7 experimental runs with emitter $D$.

\subsection{Field experiments}

Field experiments were conducted with a drip unit at the experimental fields of the Escuela Técnica Superior de Ingeniería Agronómica, Alimentaria y de Biosistemas, coordinates $40^{\circ} 26^{\prime} 33.2^{\prime \prime} \mathrm{N}, 3^{\circ} 43^{\prime} 43.5^{\prime \prime} \mathrm{W}$. The unit was designed to irrigate an experimental vineyard plot. Although a significant variety of cases can be presented, in general terms, the unit can represent a typical rectangular drip irrigation unit. In this unit, a $50 \mathrm{~mm}$ diameter polyethylene pipe (submain) feeds 17 $42.5 \mathrm{~m}$ length and $16 \mathrm{~mm}$ diameter driplines with emitters of $q_{n}=$ $2.3 \mathrm{~L} / \mathrm{h}$, which are laterally separated by $0.5 \mathrm{~m}$. The distance between laterals is $2.5 \mathrm{~m}$ and the submain downstream end point is $29.5 \mathrm{~m}$ from the last lateral. A topographic survey of the field plot was made to include the terrain gradient in the calculations. The scheme of the drip irrigation unit is presented in Fig. 4.

The submain pipe is connected to the general pump station through a hydrant. A manometer ( $0-6$ bar, $\pm 0,4 \%$ ), and an insertion for a digital manometer and flow meter (model M- $40, Q_{n} 10 \mathrm{~m}^{3} / \mathrm{h}$ ) were installed at the upstream end of the submain in order to set $H_{O}$ and $Q_{0}$. Similar elements were installed at the downstream end of the submain. In addition, manometer connections and flowmeters (model M150, $Q_{n}$ $3 \mathrm{~m}^{3} / \mathrm{h}$ ) were installed at the downstream end of the laterals. The same digital manometers (models $2083 \mathrm{P}$ and $2082 \mathrm{P}$, precision $\pm 0.15 \%$ ) were used to measure the pressure at each manometer connection.

Both laterals and emitters to be measured were selected by following the procedure given by Juana et al. (2007). The points were located at $y / L t=0.102,0.407,0.593$, and 0.898 and $x / L=0.102$, $0.407,0.593$, and 0.898 for the submain and lateral, respectively. Two consecutive emitters were measured at each point to calculate the manufacturing coefficient of variation.

Eleven experimental runs were conducted within the self-compensating pressure range, and 32 emitters were measured to obtain the hydraulic parameters and the uniformity of irrigation. Twelve additional experiments were conducted: three with the downstream end of

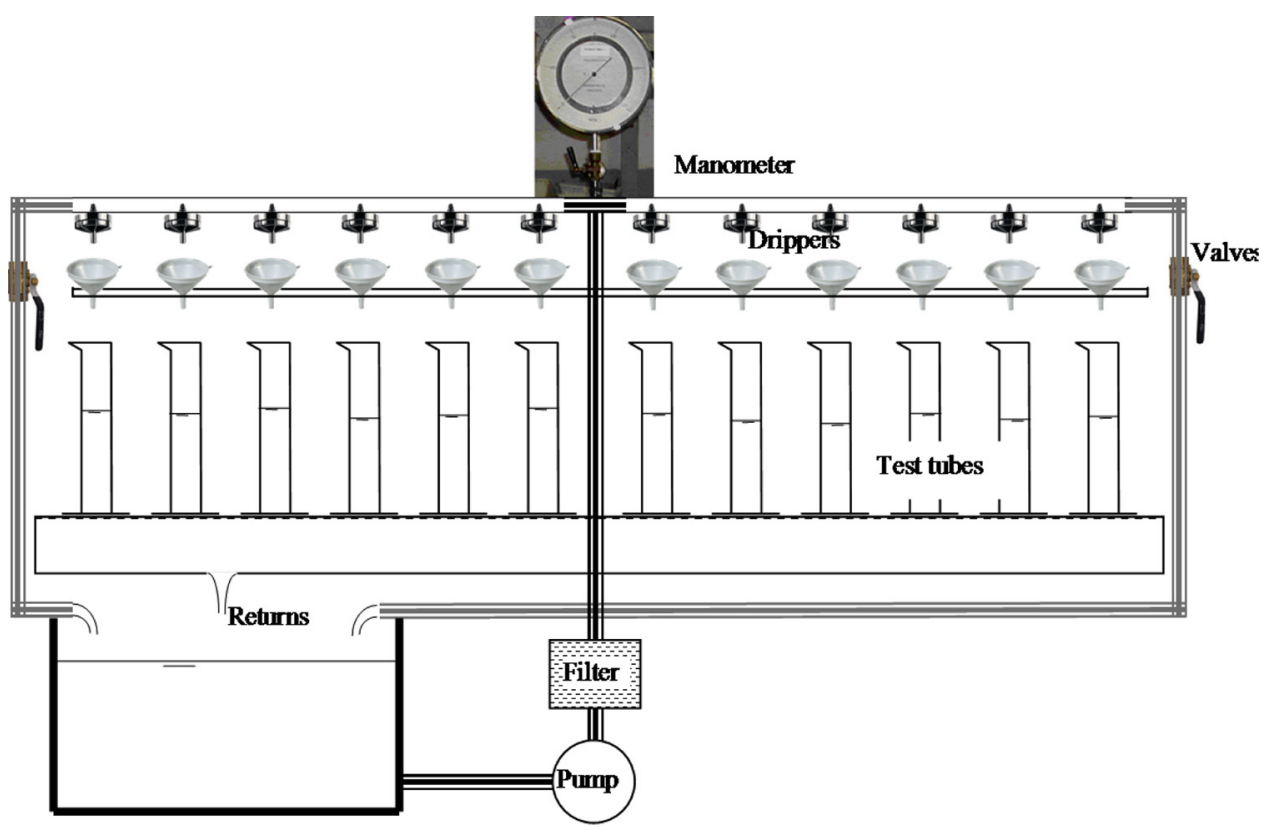

Fig. 2. Scheme of the dripper test bench. 


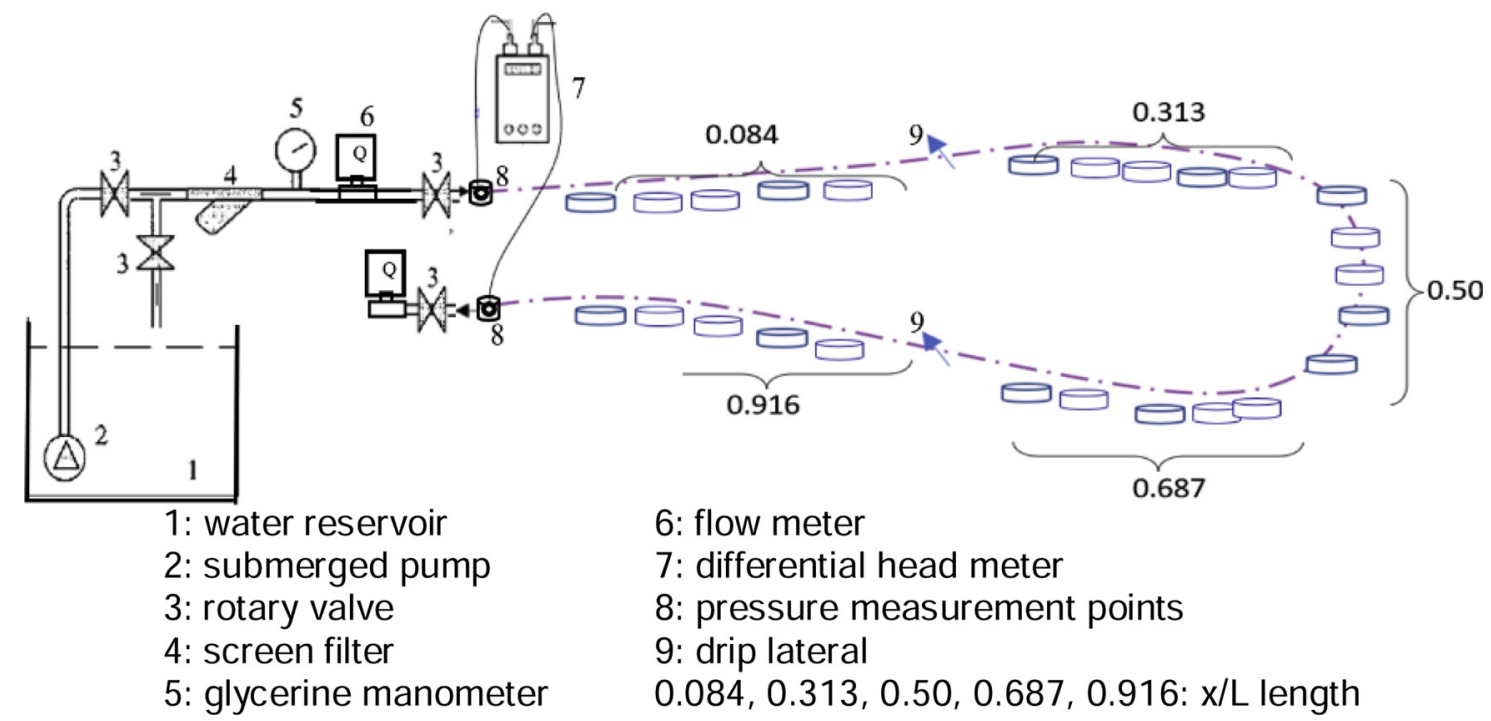

Fig. 3. Layout of the experimental installation for drip irrigation lateral testing.

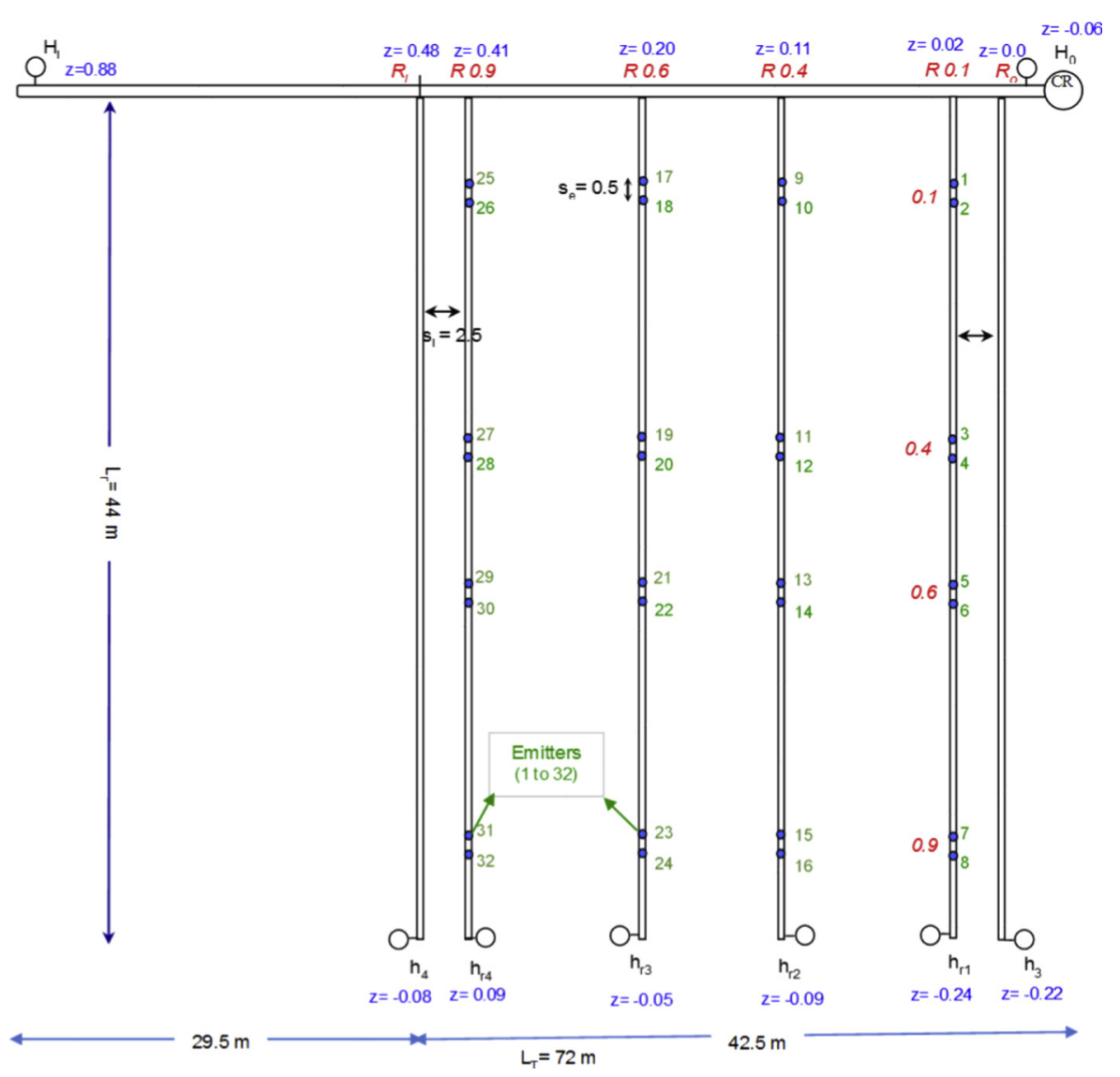

Fig. 4. Scheme of drip irrigation unit.

the submain and laterals close, three with the downstream end of the submain open, and six with the studied laterals open.

As was previously stated, the hydraulic characterisation of the submain has a number of limitations. The pressure head at each lateral insertion cannot be easily measured. To address this, we measure the pressure head at the upstream and downstream end points of the submain and, therefore, estimate the $l e_{a r}$ of each lateral insertion through an optimisation routine that minimised the differences between the estimated and the measured values.

\subsection{Proposed methods and expressions}

Iterative stepwise calculations for consecutive sections (section by section procedure) of the laterals and submain, and the classical approximated expressions (Wu and Gitlin, 1975; Wu et al., 1979; Juana et al., 2002a, 2007; Lorenzo and Juana, 2010; Zhang et al., 2013) were both used for the hydraulic characterisation of the emitters, laterals, submain, and unit.

The Blasius equation was used for the head losses calculations. The low roughness and small diameters of the PE pipes used in drip 
irrigation units yielded Reynolds numbers below $10^{5}$, which is inside the range of validity range of the Blasius. In addition, the possible laminar flow appearing at the lateral downstream end has no physical effect (Benítez and Juana, 2012). Therefore, the hydraulic gradient $I$, in a section with diameter $D$, a discharged flow $Q$, and kinematic water viscosity $\nu$, is as follows:

$I=0.0246 \nu^{0.25} Q^{1.75} D^{-4.75}$

The emitter discharge $q$, under pressure head $h$ and parameters $k$ and $x$, is as follows:

$q=k h^{x}$,

With non-compensating emitters, the average discharged flow $q_{a v}$ was estimated (dividing the total flow $Q_{0}$ by the number of emitters) for each experimental run. In addition, the average pressure head $h_{a v}$ was estimated from the pressure head at the beginning $\left(h_{0}\right)$ or the end $\left(h_{L}\right)$ of the lateral, and the lateral head losses, as follows:

$h_{a v} \cong h_{0}-\frac{m+1}{m+2} h f_{r} \cong h_{L}+\frac{1}{m+2} h f_{r}$

Where, $m$ is the flow exponent of the Blasius equation and equals $m=1.75$, and exponents $k$ and $x$ were estimated from the measured pairs $\left(q_{a v}, h_{a v}\right)$ using a minimum square regression method. As opposed to using $h_{a v}$ to determine the pressure corresponding to the average flow rate, it may be preferable use $h_{q a v}$. Both of these can be related through the exponent $x$ (a first approximation is necessary) and the lateral head losses, Juana et al. (2002a, 2002b), however, it is the experience of the authors using either of these flow rates will not result in significant differences. It is noted that there were trials with significant differences in pressure, otherwise, it would be preferable to consider the $x$ exponent declared by the manufacturer and estimate $k$.

Approximate expressions to calculate $h_{a v}$ in non-compensating laterals with the downstream end open could be deduced. However, this procedure is not proposed in this study for these types of emitters, as it is preferable to calculate them by the stepwise method, section by section.

The manufacturing coefficient of variation $\left(C V_{m}\right)$, which is the quotient between the standard deviation and the mean value, was calculated for each test, using the difference between measured $q_{i}$ and anticipated $q_{i \exp }$ discharge flows, with $k$ and $x$ values and the estimated $h_{i}$ est as follows:

$C V_{m} \cong \sigma_{\left(\frac{q_{i}}{q_{\exp }}-1\right)}=\sqrt{\frac{1}{N-1} \sum_{i=1}^{N}\left(\frac{q_{i}}{q_{\exp _{i}}}-1\right)^{2}}$

Since the pressure head varies along the lateral, the expected flow rates differ and only using the quotient between the measured flow $\left(q_{i}\right)$ and the estimated flow for the supposed pressured head values $\left(q_{i} \exp \right)$ allows isolating the manufacturing influence of the effect from different pressure head. We used the expected flow values instead of the average of the measured value because each measured non-compensating emitter operates at different pressure and thus discharges different flow rate so the average of all the analysed emitters would not be representative.

The self-compensating emitter ranges were determined by detecting significant flow variations as the pressure head varied. In this case, the $C V_{m}$ was directly determined from the measured discharged flow during the experimental runs. To simulate the operating behaviour of emitters with pressure head below the self-compensating range, the following expression, which uses logical variables, is proposed:

$q=q_{n} \cdot\left(h \geq h_{\min }\right)+q_{n} \cdot\left(\frac{h}{h_{\min }}\right)^{0.5} \cdot\left(h<h_{\min }\right)$

Three different alternatives were proposed for the head losses characterisation: first, the nominal head loss, or head losses along of the lateral length, anticipated for the emitter nominal flow was estimated; second, the equivalent length le of each emitter using the Blasius equation; and third, the $K$ friction coefficient of local head losses was also computed.

The following expressions were used for the head losses calculation in the lateral, $h f_{r}$, with self-compensating emitters and the laterals downstream end closed either using le (Eq. (6)) or $K$ (Eq. (7)).

$h f_{r}=\frac{0.0246}{2.75} \nu^{0.25} Q_{0}^{1.75} D^{-4.75} L\left(1+\frac{l e}{s}\right)$

$h f_{r}=\frac{0.0246}{2.75} \nu^{0.25} Q_{0}^{1.75} D^{-4.75} L+\frac{K}{3} \frac{L}{s}\left(\frac{4 Q_{0}}{\pi D^{2}}\right)^{2} \frac{1}{2 g}$

where, $s$ is the emitter spacing, and $g$ the gravitational constant.

Eqs. (6) and (7) are not suitable for non-compensating laterals emitters in which $h f_{r}$ exceeds 0.2 of the mean pressure head $h_{a v}$. To increase this validity range to $0.8 h_{a v}$, Juana et al. (2002a) proposed a correction coefficient dependent on $x$ and the relationship, $h f_{r} / h_{a v}$. The following expressions consider these cases.

$$
\begin{aligned}
h f_{r}= & \frac{0.0246}{2.75} \nu^{0.25} Q_{0}^{1.75} D^{-4.75} L\left(1+\frac{l e}{s}\right)\left[1-0.117 x \frac{h f_{r}}{h_{a v}}\right]^{2} \\
h f_{r}= & \frac{0.0246}{2.75} \nu^{0.25} Q_{0}^{1.75} D^{-4.75} L\left[1-0.117 x \frac{h f_{r}}{h_{a v}}\right]^{2} \\
& +\frac{K}{3} \frac{L}{s}\left(\frac{4 Q_{0}}{\pi D^{2}}\right)^{2} \frac{1}{2 g}\left[1-0.125 x \frac{h f_{r}}{h_{a v}}\right]^{2}
\end{aligned}
$$

For laterals with the downstream end open, given the measured values of $Q_{L}$ and $Q_{0}$, Benítez and Juana (2012) proposed the following expressions to estimate $h f_{r}$ :

$h f_{r}=\frac{1-r_{L}^{2.75}}{1-r_{L}} \frac{0.0246}{2.75} \nu^{0.25} Q_{0}^{1.75} D^{-4.75} L\left(1+\frac{l e}{s}\right)$

$h f_{r}=\frac{1-r_{L}^{2.75}}{1-r_{L}} \frac{0.0246}{2.75} \nu^{0.25} Q_{0}^{1.75} D^{-4.75} L+\frac{1-r_{L}^{3}}{1-r_{L}} \frac{K}{3} \frac{L}{S}\left(\frac{4 Q_{0}}{\pi D^{2}}\right)^{2} \frac{1}{2 g}$

Alternatively, the hydraulic study can be conducted using a sectionby-section procedure. In this case, starting from the downstream end section where $Q_{L}$ and $H_{L}$ are measured, the calculations are performed upwards to estimate the inlet flow $Q_{o}$ and pressure head $h_{0}$ to coincide with the respective measured quantities. In each test, to ensure the coincidence between the estimated and measured $Q_{0}$, the discharge coefficient $k$, is corrected and, for the coincidence of $h_{0}$, either $l e$ or $K$, are corrected.

Numerical routines were developed to analyse these cases. As the lateral insertion is buried, the lateral head losses were estimated using the downstream end elevation and measured pressure head and the estimated upstream end energy. The submain head losses in the lateral insertion were determined from the elevations and the measured pressure head at its upstream and downstream end sections, letting $l e_{a r}$, or $K_{r}$, vary until obtaining values that provide the coincidence between the estimated and measured pressure head. Specific $l e$ and $K$ values for each lateral were estimated using this method. In additional, generic $K$ and $l e$ values were also estimated by minimising an objective function that considers the difference between the estimated and measured values.

In this context, it is noted that the parameters related to the local head losses, le or $K$, depend fundamentally on the geometrical characteristics of the emitter within the pipe. A number of studies have been conducted to determine the hydraulic relationship between the local head losses and the pipe-emitter characteristics (Al-Amoud, 1995; Bagarello et al., 1997; Juana et al., 2002a; Lorenzo and Juana, 2010; Benítez and Juana, 2012). The characterisation of these relationships in field experiments of operating units would require additional studies that exceed the scope of the present work. 


\section{Results}

\subsection{Laboratory experiments}

\subsubsection{Non-compensating emitters}

3.1.1.1. Discharging curve and manufacturing coefficient of variation. Fig. 5 shows the values obtained in the standardised and the lateral tests of emitter C.

The results for the emitter D are shown in Fig. 6 .

Table 2 presents the nominal flow determined from both methods. The results can be classified as similar and, therefore, repeatable. Exponents $x$ of emitters were, in all cases, approximately 0.50 . The adoption of exponent $x=0.50$ and the emitter nominal flow rate $q_{n}$ obtained were considered suitable to characterise the discharging curves of emitters $C$ and D. Taking exponent $x=0.5$ would have simplified the calculations, except for the cases in which it is indicated as not valid.

The calculated $C V_{m}$ following the standardised method was $C V_{m}=0.027$ (calculated with $h=10 \mathrm{~m}$ ), while the mean value of all the tests was $C V_{m \text { av }}=0.033$, with a standard deviation $\sigma=0.0049$. The linear regression with the pressure head resulted in a slope of -0.0003 , which is a marginally decreasing slope, and a coefficient of determination $R^{2}=0.27$. In emitter $\mathrm{D}, C V_{m}=0.022$ at the nominal pressure head, while the average value of all tests was $C V_{m a v}=0.022$, with a standard deviation $\sigma=0.0047$. The linear 6 and 7 of -0.00007 and $R^{2}=0.02$. This indicated that it is insensitive to pressure changes.

The laboratory experiments with the laterals yielded $C V_{m}$ av $=$ 0.035. and a standard deviation of $\sigma=0.004$ for emitter C. In the case of laterals with emitter D, $C V_{m a v}=0.018$, with a standard deviation of $\sigma=0.010$. The values $C V_{m a v}=0.033$ and $C V_{m a v}=0.022$ obtained by the standardised method, for emitters $\mathrm{C}$ and $\mathrm{D}$, respectively, were similar. The slopes of the linear regression were -0.00007 and -0.0016 , and the coefficients of determination $R^{2}, 0.02$ and 0.31 , for emitters C and $\mathrm{D}$, respectively.

It can be concluded that the results from both methods were similar, and that non-dependence between the pressure head and $C V_{m}$ can be accepted.

3.1.1.2. Head losses in laterals and parameters of local loss, le and $K$. In lateral C, it was observed that the section of the pipe was clearly oval. This defect was repaired during the experiments; however, it was not perfectly circular for any of test. In the field, it can be expected to disappear with temperature changes.

The measured head losses, $h f_{r v}$ for the inlet nominal flow rate $Q_{o n}=286 \mathrm{~L} / \mathrm{h}$ in the lateral with emitter C (100 m pipeline with drippers of $q_{n}=2.15 \mathrm{~L} / \mathrm{h}$ at $s=0.75 \mathrm{~m}$ intervals) was $h f_{r n}=1.61 \mathrm{~m}$. However, the behaviour of the measured $Q_{0}-h f_{r}$ points was different to that anticipated and, it is surmised that, if the oval shape had been fully repaired, the differences would have been smaller. By fitting a power function to $Q_{o^{-}} h f_{r}$, the obtained exponent was 1.45 , for both the experiments performed on the first day and in the following week, as shown in Fig. 7.

It is surmised that, the higher flow rates (and higher pressures) made the cross section of the pipe more circular and, therefore, these results could be more representative. For this reason, a lower envelope curve with an exponent $m=1.75$ was also represented. With this curve, the head losses for the nominal flow rate would be $h f_{r n}=1.40$ (see Fig. 7). This implies that, if the tests are normalised, it would be advisable to treat the pipe before installation if the factory material is not sufficiently flexible that, under normal working pressures, the pipeline has a circular cross section.

Lateral D did not present any deformation and the curve $Q_{0}-h f_{r}$ exhibited a shape closer to the anticipated behaviour, as shown in Fig. 8.

Small hysteresis effects were observed on both laterals. For the same flow rate, in the first phase with increasing flow, the head losses were marginally greater than in the subsequent decreasing phase.

In each experiment, for each pair $Q_{o}-h f_{r}$, Eqs. (8) and (9) were used to calculate $l e$ and $K$. The estimated $l e$ and $K$ values for the lateral with emitters $\mathrm{C}$ are shown in Fig. 9. The dashed lines in Fig. 9 (le $=0.197$ and $K=0.520$ ) correspond to the head losses for the nominal flow ( $h f_{r}$ ${ }_{n}=1.40 \mathrm{~m}$ for $Q_{o n}=286 \mathrm{~L} / \mathrm{h}$ ). Fig. 10 shows the equivalent calculations for the lateral with emitters D. The $l_{e}$ and $K$ values for $q_{n}$ are represented with dashed lines.

Note: 1 st and 2nd indicate experiments day, respectively.

From Fig. 10, it can be seen that a smaller hysteresis effect occurs with higher values in the increasing phase $(a)$ than in the decreasing phase $(b)$.

In lateral $\mathrm{C}$, the behaviour of the head losses with the flow rate and an exponent $m$ smaller than 1.75 is the reason that $l e$ and $K$ decrease with increasing head losses (also the inlet flow). If the pipe section is not perfectly circular, and is oval, the estimated head losses are smaller than the measured ones and, when calculating either $K$ or $l e$ to coincide the estimated and measured head losses, these are overestimated. The tests with higher pressures, being non-compensating emitters, are those that have higher discharge and head losses. When increasing the pressure, the section is closer to the circular shape, this makes that the errors are less important in the tests with higher head losses. As a consequence, the $m$ exponent (estimated as the slope of the curve log $(h f)-\log (Q)$ ) would be smaller for the oval shape since the differences between the measured points with low flow for both circular and oval shapes are greater than those with large flow values.

In lateral $\mathrm{D}$, the results were as anticipated, an approximately constant $l e$ value and a decreasing $K$ value. With increasing flow, the head losses increase at a different rate depending on whether $l e$ or $K$ is used, because $Q$ power is 1.75 in the first case (hydraulically smooth regime) and 2 in the second case (fully rough regime). The operating conditions are similar to the hydraulically smooth regime, in particular for the lower flow rates, and a decreasing $K$ coefficient with $h f r$ is observed. This phenomenon decreases as flow increases because of the fully turbulent flow, and the relationship $K-h f_{r}$ would become horizontal if the flow $Q$ were significantly increased.

Table 3 presents the results of the parameters estimated in the laboratory trials. According to the graphs, the values of the standard deviation, $\sigma, l e$, and $K$ were significantly lower in the lateral $\mathrm{D}$, with $l e$ also significantly lower than $K$.

\subsubsection{Self-compensating emitters}

3.1.2.1. Discharging curve and manufacturing coefficient of variation. The self-compensating range of emitter A starts at a $4 \mathrm{~m}$ pressure head, as specified by the manufacturer. The discharged flow rate first decreased marginally with increasing pressure $\left(5 \leq h_{a v}(\mathrm{~m}) \leq 20\right)$, and then increased marginally $\left(20 \leq h_{a v}(\mathrm{~m}) \leq 34\right)$, as can be seen in Fig. 11 . The measured flow was between $5 \%$ and $11 \%$ greater than the

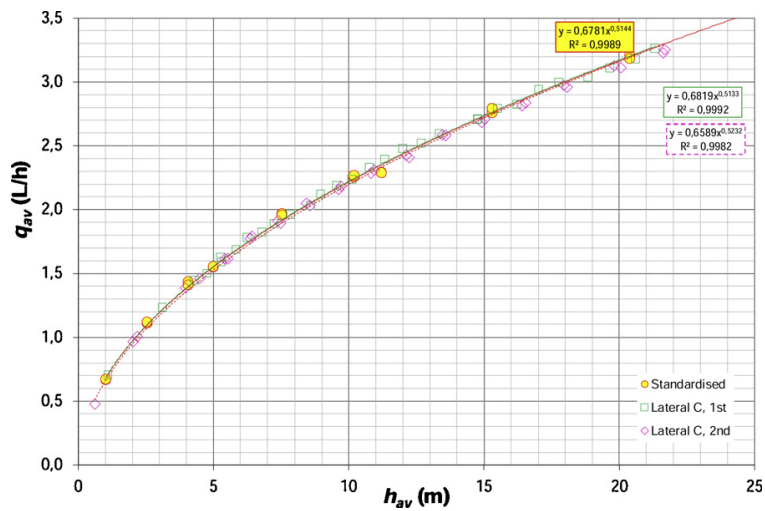

Fig. 5. Discharge curve of emitter $\mathrm{C}$ obtained by standardised tests and by lateral tests, carried out on different days. 


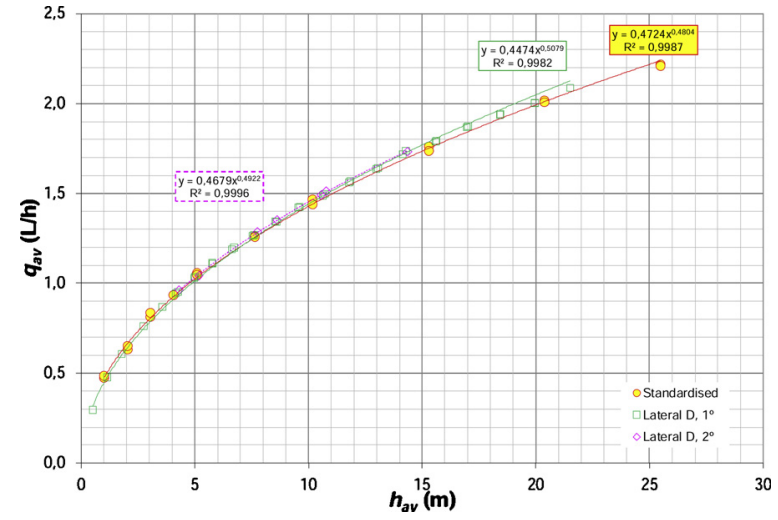

Fig. 6. Discharging curve of emitter D obtained by standardised tests and in lateral tests, carried out on different days.

Table 2

Nominal flow rate and manufacturing coefficient of variation obtained by the standardised experiments and by the proposed method in laterals.

\begin{tabular}{|c|c|c|c|c|c|}
\hline \multirow[t]{2}{*}{ Variable } & \multirow[t]{2}{*}{ Emitter } & \multicolumn{2}{|l|}{ ISO } & \multicolumn{2}{|c|}{ Lateral experiment } \\
\hline & & Manufacturer & $\begin{array}{l}\text { Bench } \\
\text { experiment }\end{array}$ & $1^{\circ}$ & $2^{\circ}$ \\
\hline Emitter nominal & $\mathrm{C}$ & 2.15 & 2.24 & 2.25 & 2.22 \\
\hline $\begin{array}{l}\text { flow rate, } q_{n} \\
(\mathrm{~L} / \mathrm{h})\end{array}$ & $\mathrm{D}$ & 1.50 & 1.44 & 1.46 & 1.47 \\
\hline Manufacturing & $\mathrm{C}$ & \multicolumn{2}{|c|}{$0.033(\sigma=0.0050)$} & \multicolumn{2}{|c|}{$0.035(\sigma=0.0042)$} \\
\hline $\begin{array}{l}\text { coefficient } \\
\text { of variation, } \\
C V_{m} a v\end{array}$ & $\mathrm{D}$ & \multicolumn{2}{|c|}{$0.022(\sigma=0.0047)$} & $0.018(\sigma$ & $=0.0102)$ \\
\hline
\end{tabular}

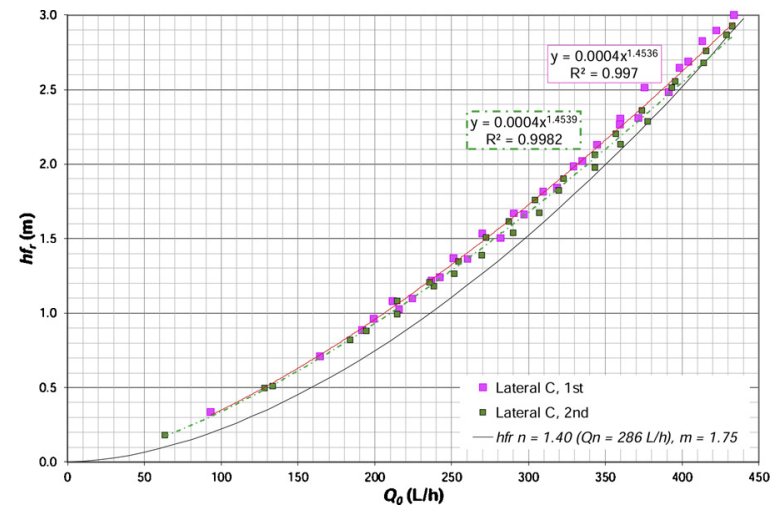

Fig. 7. Head losses on lateral $\mathrm{C}$ as a function of the inlet flow rate, adjustment curves and Blasius' expression curve (exponent $m=1.75$ ) that adjusts at the bottom.

indicated nominal flow $q_{n}=2.3 \mathrm{~L} / \mathrm{h}$.

The average flow measured in the self-compensating range was $q_{a v}=2.43 \mathrm{~L} / \mathrm{h}$, therefore, this value was proposed to characterise the emitters with pressure heads greater than $h \min =4.13 \mathrm{~m}$. A small hysteresis effect was observed. Measured flows were greater during the first phase with increasing pressures. A priori, it could be anticipated that the emitters behave as a non-compensating emitter outside the selfcompensating range, in particular when below the minimum limit of this range. For this reason, it was attempted to fit the points obtained in the tests below the self-compensating range to a common non-compensating discharge curve with $x=0.5$. Following this procedure, we observed a good agreement between the points and the fitting curve, as shown in Fig. 11. For this reason, a discharging curve with $x=0.5$ is proposed to characterise emitters with operating pressures smaller than $h \min =4.13 \mathrm{~m}$.

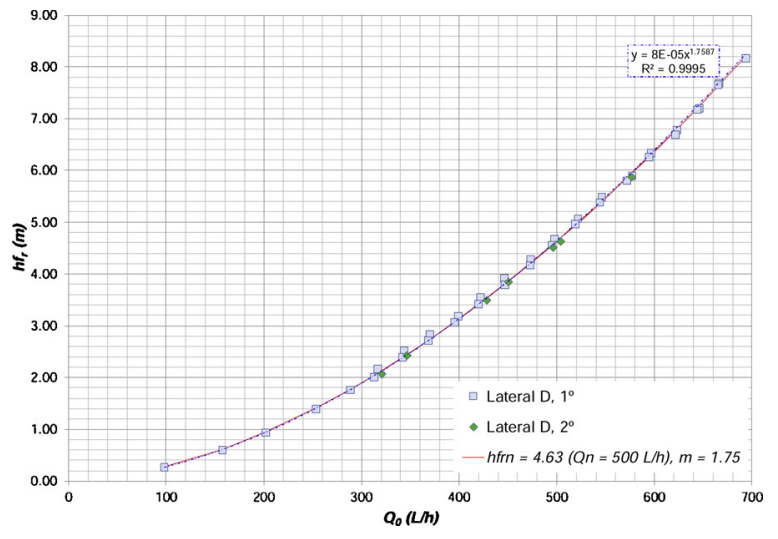

Fig. 8. Head losses on lateral $D$ as a function of the inlet flow rate, potential adjustment and Blasius' expression curve (exponent $m=1.75$ ).

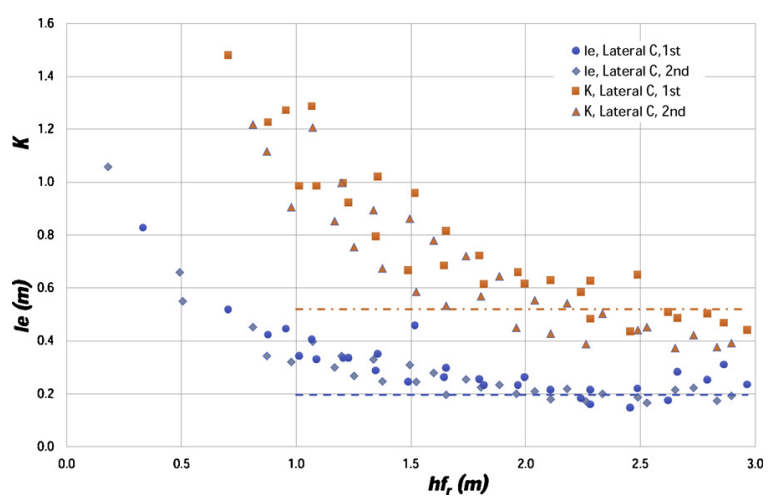

Fig. 9. $l e$ and $K$ local losses parameters in the lateral $\mathrm{C}$.

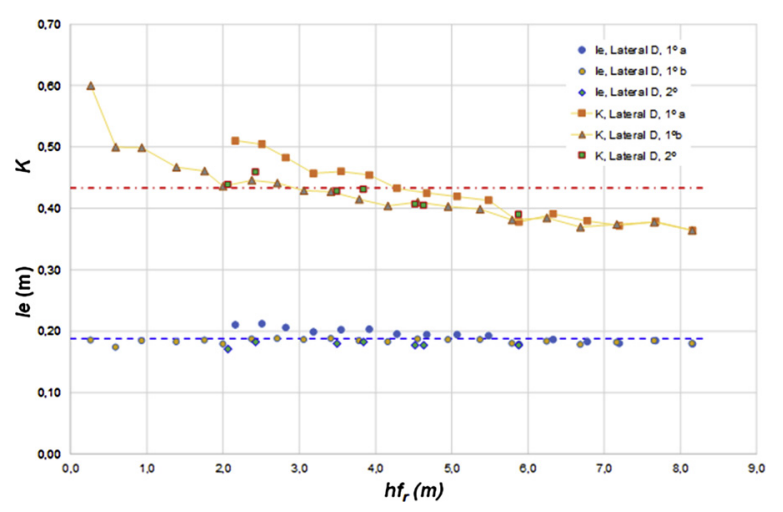

Fig. 10. le and $K$ local losses parameters in the lateral D.

Note: $a$ indicates increasing phase and $b$ decreasing phase; 1 st and 2nd indicates experiments day.

Table 3

Estimated head losses for the nominal flow, $l e$ and $K$ parameters.

\begin{tabular}{|c|c|c|c|c|c|c|c|}
\hline \multirow[t]{2}{*}{ Emitters } & \multirow[t]{2}{*}{ Statistic } & \multicolumn{2}{|l|}{$h f_{r n}$} & \multicolumn{2}{|l|}{ le } & \multicolumn{2}{|l|}{ K } \\
\hline & & $1^{\circ}$ & $2^{\circ}$ & $1^{\circ}$ & $2^{\circ}$ & $1^{\circ}$ & $2^{o}$ \\
\hline Lateral C & average & 1.61 & 1.56 & 0.307 & 0.301 & 0.849 & 0.834 \\
\hline$\left(Q_{n}=286 \mathrm{~L} / \mathrm{h}\right)$ & $\sigma$ & $0.045^{*}$ & $0.043^{*}$ & 0.134 & 0.180 & 0.490 & 0.639 \\
\hline Lateral D & average & 4.63 & 4.57 & 0.188 & 0.178 & 0.429 & 0.425 \\
\hline$\left(Q_{n}=500 \mathrm{~L} / \mathrm{h}\right)$ & $\sigma$ & $0.064^{*}$ & $0.026^{*}$ & 0.009 & 0.004 & 0.052 & 0.023 \\
\hline
\end{tabular}

Note: (*) Represents the standard error in the $h f_{r}$ estimation through a potential function $c \cdot Q_{0}{ }^{m}$. 


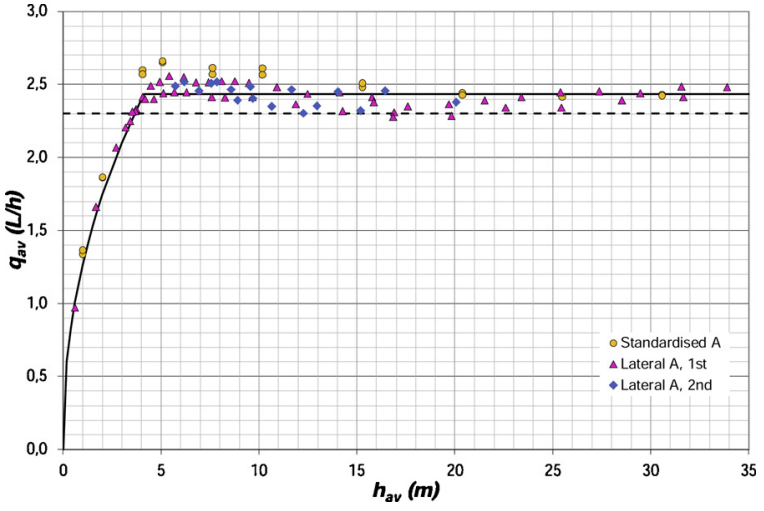

Fig. 11. Discharging curves obtained with the standardised tests and with the lateral tests, emitter A.

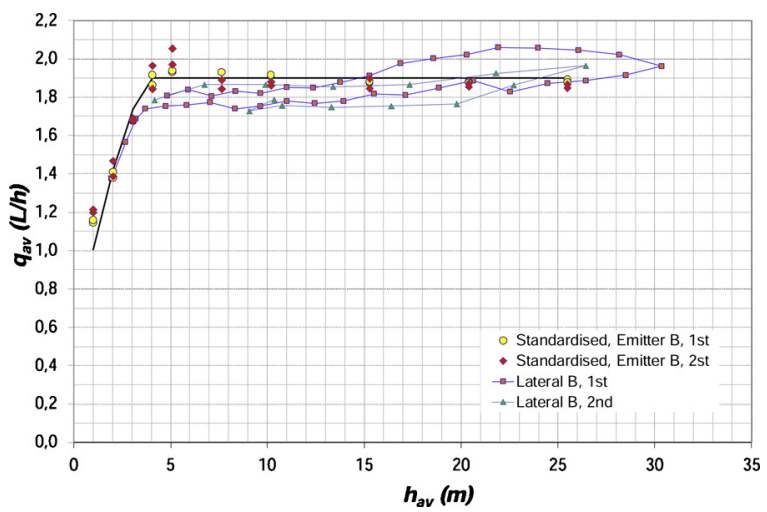

Fig. 12. Discharging curves obtained with the standardised tests and with the lateral tests, emitter B.

Fig. 12 shows the results for emitter $\mathrm{B}$. The measured flow rate exceeded the manufacturer specification $\left(q_{n}=1.6 \mathrm{~L} / \mathrm{h}\right)$. In this case, the observed behaviour with the standardised experiments was better than that observed during the lateral experiments, in particular in the first round, in which variability and hysteresis were greater.

Table 4 presents the results referred to the manufacturing coefficient of variation.

The linear relationship between $C V_{m}$ and the operating pressure head was negligible: the slopes of a linear regressions were $-0.0003(R$ $\left.{ }^{2}=0.2\right)$ and $1.3 \cdot 10^{-5}\left(R^{2}=0.001\right)$ for emitters A and B, respectively.

3.1.2.2. Head loss in laterals and parameters of local losses, le and $K$. The variability of the measured flow was smaller for the self-compensating emitters than the non-compensating ones, even if the laterals were open at the downstream end point. The measurements obtained in the experiments conducted with the pressure head within the selfcompensating range were such that $l e$ and $K$ could be estimated by Eqs. (5) and (6). Table 5 and Figs. 13 and 14 shows the results of the conducted experiments. The measured nominal average flow was considered for the calculations.

Fig. 14 shows the estimated results of $l e$ and $K$ for emitter B.

From Figs. 13 and 14, it can be observed that le performs better than $K$ because, as opposed to $K$, it remains constant for different $h f$ values. It means that le values do not show relevant variations as the discharging flow varies, in comparison with $K$, that presents a decreasing tendency with the increasing flow.

Finally, for the self-compensating emitters, the suitability of the characterised discharge curve to allow a proper simulation of the laterals was tested. For this purpose, two tests were conducted in which the flow rates of the 25 emitters were measured, with the downstream ends open and the downstream end pressure heads smaller than the lower limit of the self-compensating range. Fig. 15 shows the estimated and measured results from these two experiments.

From Fig. 15 it can be observed that the proposed methodology yields results similar to those obtained by the standardised method in the laboratory experiments.

\subsection{Field experiments}

\subsubsection{Unit irrigation with self-compensating emitter}

3.2.1.1. Irrigation uniformity tests. The average flow rate of all emitters, including all tests (11 tests $\times 32$ emitters $=352$ values), was $q_{a v}=2.26 \mathrm{~L} / \mathrm{h}$ and the manufacturing coefficient of variation $C V_{m}=0.029$.

The applied water distribution function $(F)$ of the eleven tests were similar, as shown in Fig. 16. The flow rates of each test yielded an average coefficient of variation $C V_{m a v}=0.027$. If the average value of each location is calculated and the distribution curve of these average values are shown, the thickest black line in Fig. 17 is obtained. The coefficient of variation of this average distribution in the 32 different locations was $C V=0.019$, which reports about the average or global distribution of the water received in the different points throughout the campaign, while the previous coefficient of variation, $C V=0.027$, indicates individual irrigation as being more optimal, however, it can also indicate experimental errors. From the average distribution functions in Fig. 16, it can be observed that the $2^{\text {nd }}$ and $4^{\text {th }}$ drippers, both in the first lateral, were the ones that discharged the smallest amount of water, while the $17^{\text {th }}$ (first of the third lateral) and the $15^{\text {th }}$ (seventh of the second lateral) discharged the most water.

An irrigation system with $C V=0.027$ would give a $U D_{1 / 4}=0.966$ and, if the irrigation depth is considered to be equal to the depth of the smallest quarter, the flow rate of each irrigation would be assumed to be $q_{r}=2.26 \times 0.966=2.18 \mathrm{~L} / \mathrm{h}$. Under these considerations, in different irrigation systems there could be discrepancies in different locations, but overall, if the determined average distribution is accepted, only 2 emitters would receive less water than the one considered, as shown in Fig. 17.

3.2.1.2. Discharge flow rate as a function of inlet pressure head. Fig. 18 shows the measured average discharged flow $q_{a v}$ compared to the pressure head $H_{O}$ of the unit for eleven tests, and a further two with pressures below the minimum value of the self-compensating range. Points were fitted to Eq. (5) with $q_{n}=2.26 \mathrm{~L} / \mathrm{h}$ and $H_{O \text { min }}=6.25 \mathrm{~m}$. Below a pressure head $H_{O}=6.25 \mathrm{~m}$, the unit starts to reduce its flow. Therefore, it is not practical to operate either below or above $H_{O}=6.25 \mathrm{~m}$ because of the flow reduction in the first case, or the increase of the consumed energy in the second case. The value of $C V_{m}$ does not also increase outside the self-compensating range.

In general terms, it can be assumed that $C V_{m}$ does not depend on $H_{O}$. However, the initial assumptions can vary depending on the utilisation. Under these circumstances, it is worth testing that $C V_{m}$ remains independent of the pressure head. A Spearman rank-order correlation coefficient test between $H_{O}$ and $\mathrm{CVm}$ was determined, which indicated that the independence of the measured values cannot be rejected ( $p$ value $=0.43$ ) at $\alpha=0.01$.

Table 4

Nominal flow and manufacturing coefficient of variation with standardised and lateral experiments operating within the self-compensating range.

\begin{tabular}{lcccc}
\hline Variable & \multirow{2}{*}{ Emitter } & \multicolumn{2}{l}{ ISO } & \multirow{2}{*}{ Lateral experiment } \\
\cline { 3 - 4 } & & Manufacturer & Bench experiment & \\
\hline \multirow{2}{*}{$q_{n}(\mathrm{~L} / \mathrm{h})$} & $\mathrm{A}$ & 2.3 & 2.52 & 2.43 \\
& $\mathrm{~B}$ & 1.6 & 1.90 & 1.83 \\
$C V m a v$ & $\mathrm{~A}$ & $0.035(\sigma=0.006)$ & $0.029(\sigma=0.006)$ \\
& $\mathrm{B}$ & $0.026(\sigma=0.003)$ & $0.019(\sigma=0.001)$
\end{tabular}


Table 5

Estimated head losses for the nominal flow, le and $K$ parameters.

\begin{tabular}{|c|c|c|c|c|c|c|}
\hline \multirow[t]{2}{*}{ Emitter } & \multirow[t]{2}{*}{ Statistic } & \multirow[t]{2}{*}{$h f_{r n}$} & \multicolumn{2}{|l|}{ le } & \multicolumn{2}{|l|}{$K$} \\
\hline & & & $1^{\circ}$ & $2^{\circ}$ & $1^{\circ}$ & $2^{\circ}$ \\
\hline \multirow[t]{2}{*}{ Lateral A $\left(Q_{n}=325 \mathrm{~L} / \mathrm{h}\right)$} & average & 3.16 & 0.77 & 0.81 & 2.06 & 1.97 \\
\hline & $\sigma$ & $0.07^{*}$ & 0.045 & 0.035 & 0.108 & 0.166 \\
\hline \multirow[t]{2}{*}{ Lateral B $\left(Q_{n}=311 \mathrm{~L} / \mathrm{h}\right)$} & average & 2.22 & 0.42 & 0.41 & 1.09 & 0.96 \\
\hline & $\sigma$ & $0.08^{*}$ & 0.039 & 0.021 & 0.100 & 0.125 \\
\hline
\end{tabular}

Note: (*) Represents the standard deviation in the $h f_{r}$ estimation through a potential function $c \cdot Q_{0}{ }^{m}$; 1st and 2nd indicate first and second experiments day, respectively.

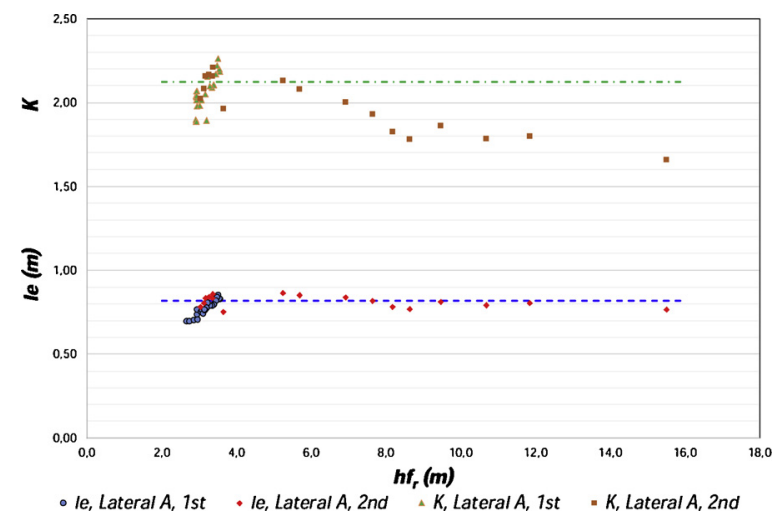

Fig. 13. le and $K$ parameters lateral $\mathrm{A}$.

Note: Dashed line corresponds to the values of $l e$ and $K$ obtained in the nominal head losses (Table 5) with the Blasius' equation.

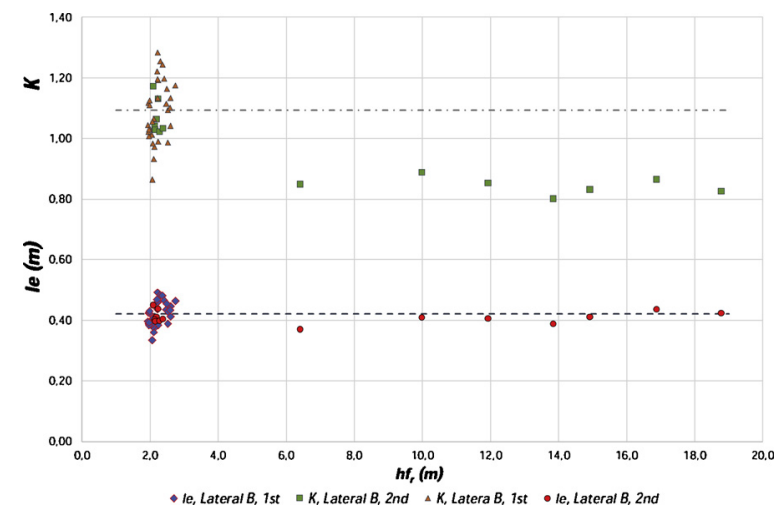

Fig. 14. le and $K$ parameters lateral $\mathrm{B}$.

Note: Dashed line corresponds to the values of $l e$ and $K$ obtained in the nominal head losses (Table 5) with the Blasius' equation.

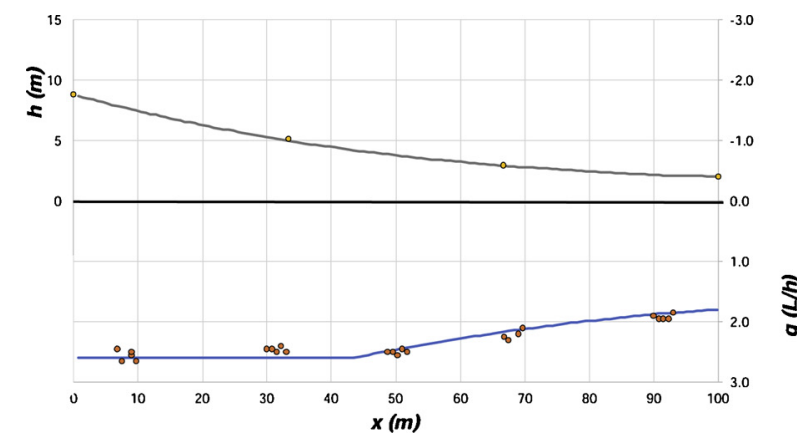

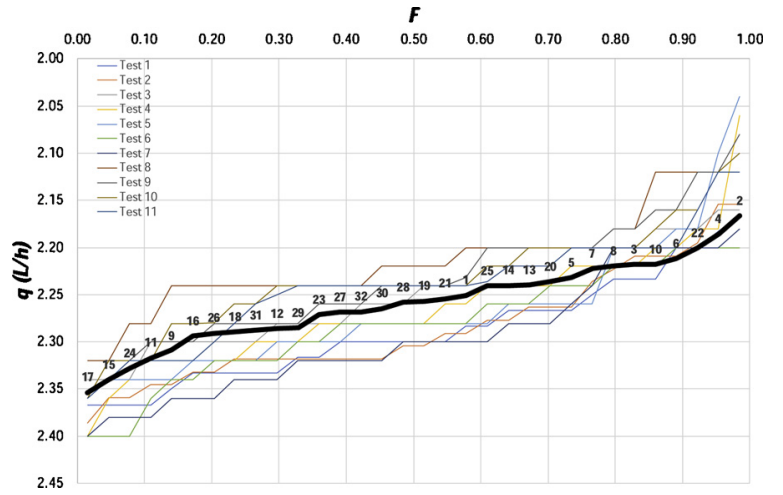

Fig. 16. Water distribution functions in the 11 tests and the average values of each location (numbers indicate emitters).

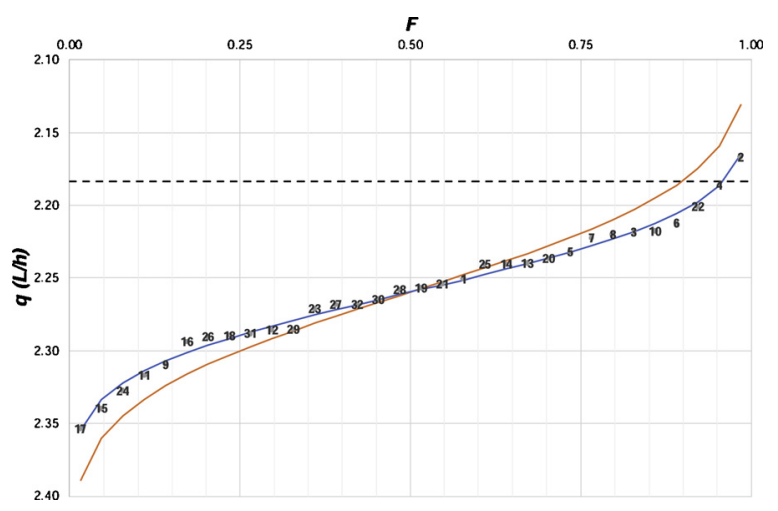

Fig. 17. Water distribution of an individual irrigation, with its low quarter flow $\left(q_{1 / 4}\right)$, and average water distribution function.

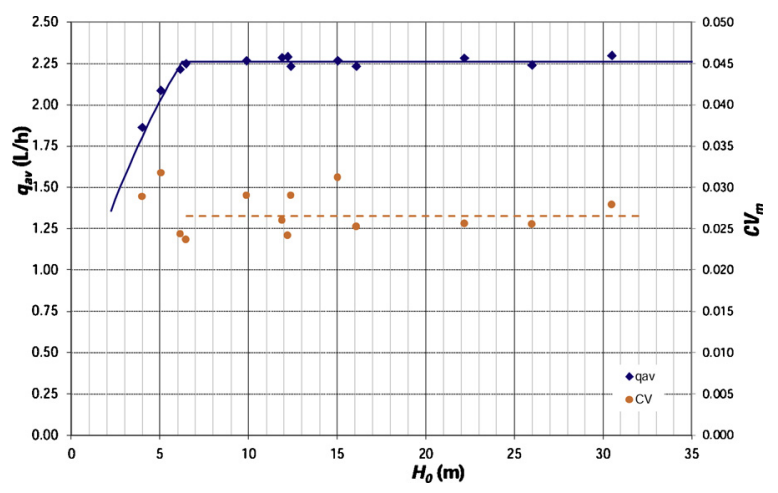

Fig. 18. Average flow rate, $q_{a v}$, and manufacturing coefficient of variation, $C V_{m}$, of the emitters, as a function of head pressure $H_{0}$.

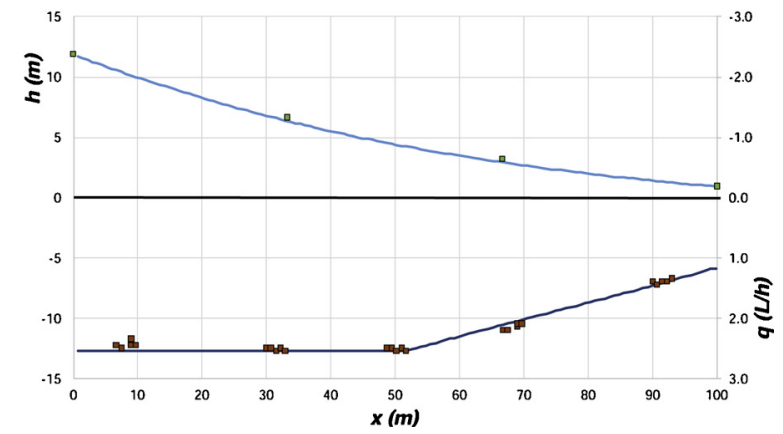

Fig. 15. Measured (a) and simulated (b) values of emitter A. 
The graph shows the coefficient of variation of each test and the average value within the compensation range, which, as was noted, was $C V_{m a v}=0.027$.

The curves $H_{O^{-}} q_{a v}$ (Fig. 18) and $h_{\mathrm{av}} q_{a v}$ (Fig. 12) present similar shapes. The former was chosen to be used as because $H_{O}$ is more easily controlled and operated.

3.2.1.3. Head loss and pressure distribution. As discussed above, the head losses and the pressure distribution were estimated using two different procedures: first, the global parameters were obtained for all the tests and, second, the individual parameters for each test were used to obtain the average values and thus appreciate the possible errors more easily.

As previously mentioned, the head losses were estimated from the pressure head measurements at the upstream and downstream end points in the submain, together with differences in the elevation levels. In each test, the pressure head at the end of the selected laterals and their elevation levels were also measured. These values allowed the pressure head at each point of the submain and each analysed lateral to be estimated. These data also allowed $l e$ and $l e_{a r}$ to be estimated. The estimates were obtained by minimising both the sum of the second power of the differences between the measured and the estimated with $l e$ and $l e_{a r}$ values, and the mean absolute deviation for different distribution of head losses between the laterals and submain.

Fig. 19 shows the fitted solution that corresponds to $l e_{i}=0.67,0.46$, 0.49 , and 0.43 , for the four tested laterals, and $l e_{a r}=0.80$. The estimated head losses of the laterals were greater than those obtained for the submain. From this, we observed that the optimum $l e_{a r}$ value was significantly more sensitive than le to the head losses distribution between the laterals and submain. Therefore, we opted to estimate a different $l e$ value for each lateral (the combined $l e$ value considering all the laterals is $l e=0.51 \mathrm{~m}$ ). This implies that the head losses of the first lateral are underestimated, and that the head losses of the last lateral are overestimated. However, the values obtained for the first lateral are in good agreement with those expected if the dripper values were obtained using the expressions from Juana et al. (2007).

Of the 12 tests, in eight there were data of the laterals. A separate colour was used for each lateral of these tests in Fig. 19, where four points of same colour correspond to the four laterals.

Table 6 presents the mean absolute deviations $(M A D)$ between the measured and estimated head losses of the conducted tests.

With the new data, the unit can be simulated and, if $H_{O}=6.5 \mathrm{~m}$, which is marginally greater than $h \mathrm{~min}$, the energy $H$ can be obtained at any point. Fig. 20 shows $H$ along the accumulated distance to the upstream end accumulated length $L a$.

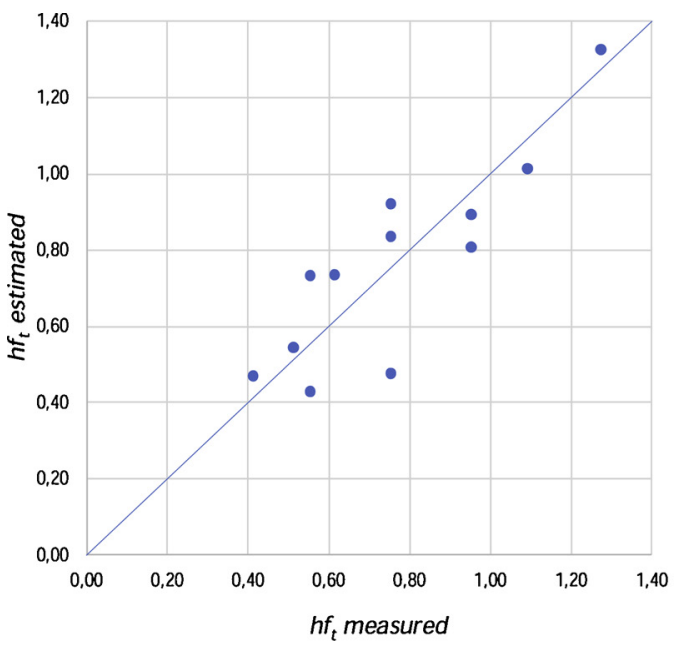

Table 6

Mean absolute deviations of the measured and estimated head losses.

\begin{tabular}{llllll}
\hline & $h f_{t}$ & $h f_{r 1}$ & $h f_{r 2}$ & $h f_{r 3}$ & $h f_{r 4}$ \\
\hline$M A D(\mathrm{~m})$ & 0.115 & 0.241 & 0.177 & 0.149 & 0.143 \\
\hline
\end{tabular}

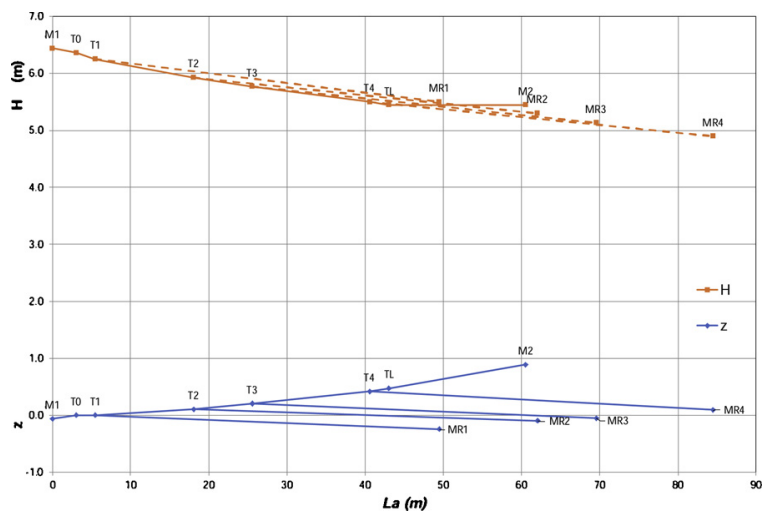

Fig. 20. Energy line $H$ and geometric $z$ along the unit.

If $l e$ and $l e_{a r}$ are modified, the simulated values of the pressure head change, either converging on or moving away from the observed values. For each test, parameters that produce a perfect fit in the corresponding head loss can be determined. Proceeding in this manner, there are as many equations as there are unknowns. The emitter flow was estimated using the characterisation realised $\left(q=q_{a v}=2.26 \mathrm{~L} / \mathrm{h}\right.$, when the pressure is greater than the minimum limit of the self-compensation range specified by the manufacturer, $h \mathrm{~min}=0.4 \mathrm{bar}$, and decreasing with an expression of orifice-type for smaller values). However, in this simulation, the estimated total flow differs from that measured at the head. From this procedure, the results obtained are presented in Table 7.

As in the previous section, the first lateral exhibited a greater $l e$ value. In addition, the differences in $l e 1$ among the tests were smaller than in the previous calculation. Similarly, $l e_{a r}$ is more variable from one test to another.

\section{Conclusions}

Trials conducted with drip laterals in the laboratory allowed the precise determination of the discharging curve, the manufacturing coefficient of variation, and the self-compensating range of the emitters.

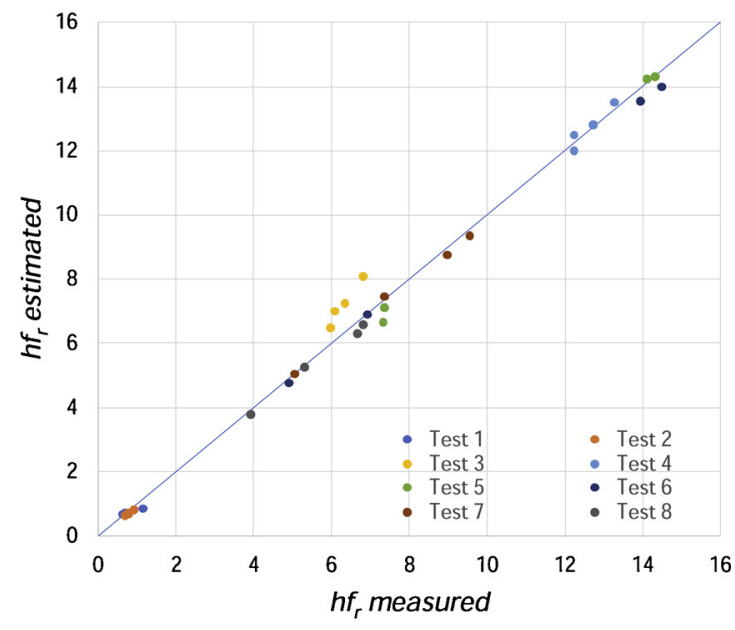

Fig. 19. Measured and estimated head loses in (a) submain, $h f_{t}$ and (b) laterals, $h f_{r}$. 
Table 7

Equivalent lengths obtained from the individual experiments, mean values and coefficient of variation of the method with the free discharge at the downstream end. Relative error of the inlet flow rate simulated and measured $e_{r Q}$.

\begin{tabular}{|c|c|c|c|c|c|c|c|c|c|c|}
\hline \multirow[t]{2}{*}{ Parameter } & \multicolumn{2}{|c|}{ Downstream end closed } & \multicolumn{8}{|c|}{ Downstream end open } \\
\hline & 1 & 2 & 3 & 4 & 5 & 6 & 7 & 8 & Mean & $C V$ \\
\hline le1 & 1.29 & 0.89 & 0.63 & 0.72 & 0.71 & 0.73 & 0.71 & 0.74 & 0.71 & 0.05 \\
\hline le2 & 0.47 & 0.73 & 0.46 & 0.51 & 0.50 & 0.53 & 0.50 & 0.52 & 0.50 & 0.04 \\
\hline le3 & 0.41 & 0.73 & 0.47 & 0.55 & 0.55 & 0.54 & 0.51 & 0.56 & 0.53 & 0.06 \\
\hline le4 & 0.25 & 0.61 & 0.46 & 0.44 & 0.54 & 0.44 & 0.43 & 0.46 & 0.46 & 0.09 \\
\hline$l e_{a r}$ & 3.32 & 0.69 & 0.32 & 1.33 & 0.49 & 1.43 & 0.74 & 0.18 & 0.75 & 0.69 \\
\hline$e_{r Q}$ & -0.04 & -0.03 & 0.01 & -0.01 & -0.03 & -0.03 & -0.02 & -0.01 & -0.02 & - \\
\hline
\end{tabular}

The values obtained in the experiments were similar to those obtained by the standardised method.

For the analysed laterals, the parameter le yielded results more accurate than those obtained using $K$ due to its lower dependence on the circulating flow. In the case of self-compensating emitters, if the head losses on laterals are small, it is convenient to include tests with the downstream end of the lateral open to estimate the local head losses. In the case of non-compensating drippers, it is not necessary, if tests with significantly different pressures are available.

For the non-compensating emitters analysed in this study, adopting an exponent $x=0.5$ could have positive effects. In this way, the discharge curve would only be defined by the nominal flow. In self-compensating emitters, the nominal pressure could be replaced by the minimum pressure of the compensation range, assuming a constant flow rate for higher pressures, however, for lower pressures an orifice type equation $(x=0.5)$ could suffice.

The experiments conducted on the field unit allowed the determination of the discharging curve and the coefficient of variation, as well as a reasonable estimate of the localised losses in laterals and submain.

The estimated response of the average flow and its uniformity to the pressure at the inlet of the unit can be used for managing an irrigation system, both the pressure itself and the irrigation time for the desired irrigation depth.

\section{Acknowledgments}

Diego Chamba wants to thank Secretaría de Educación Superior, Ciencia, Tecnología e Innovación (SENESCYT) and Instituto de Fomento al Talento Humano, of the Ecuador Government for supporting its PhD studies (grant. № 2015-AR7L7871).

\section{References}

Al-Amoud, A.I., 1995. Significance of energy losses due to emitter connections in trickle irrigation lines. J. Agric. Eng. Res. 60 (1), 1-5.

ASAE, 1998. ASAE Standards. ASAE, 2950 Niles Road, St. Joseph, MI, USA, pp. 49085-49659.

Bagarello, V., Ferro, V., Provenzano, G., Pumo, D., 1997. "Evaluating pressure losses in drip-irrigation lines". J. Irrg. Drain Eng. 123 (1), 1-7.

Benítez, L., Juana, L., 2012. Pérdidas de carga localizadas en ramales de riego por goteo, aspectos a considerar en su determinación. XXIX Congreso Nacional de Riegos, Albacete.

Bralts, V.F., Edwards, D.M., 1986. Field-Evaluation of drip irrigation submain units. Trans. ASAE 29 (6), 1659-1664.

Bralts, V.F., Edwards, D.M., Wu, I.P., 1987. Drip irrigation design and evaluation based on the statistical uniformity concept. Advances in Irrigation Vol. 4https://doi.org/10. 1016/B978-0-12-024304-4.50005-5.

Bralts, V.F., Kesner, D., 1983. Drip irrigation field uniformity estimation. Trans. ASAE 26 (5), 1367-1374.

Chamba, D., Zubelzu, S., Juana, L., 2019. Energy, cost and uniformity in the design of drip irrigation systems. Biosyst. Eng. 178 (2019), 200-218. https://doi.org/10.1016/j. biosystemseng.2018.11.01.

FAO, 1986. In: FAO (Ed.), Riego Localizado. Estudio FAO Riego Y Drenaje № 36, Roma.

ISO, 2004. ISO 9261:2004. Agricultural Irrigation Equipment - Emitters - Specification and Test Methods. Geneva, Switzerland. .

Juana, L., Rodríguez-Sinobas, L., Losada, A., 2002a. Determining minor head losses in drip irrigation laterals. I: methodology. J. Irrig. Drain. Eng. 128 (6), 376-384. https://doi.org/10.1061/(ASCE)0733-9437(2002)128:6(376).

Juana, L., Rodríguez-Sinobas, L., Losada, A., 2002b. Determining minor head losses in drip irrigation laterals. II: experimental study and validation. J. Irrig. Drain. Eng. 128 (6), 385-396. https://doi.org/10.1061/(ASCE)0733-9437(2002)128:6(385).

Juana, L., Rodríguez-Sinobas, L., Sánchez, R., Losada, A., 2007. Evaluation of drip irrigation: selection of emitters and hydraulic characterization of trapezoidal units. Agric. Water Manag. 90, 13-26. https://doi.org/10.1016/j.agwat.2007.01.007.

Lorenzo, D., Juana, L., 2010. Alternativas para una norma sobre pérdidas de carga en tuberías emisoras. Presentación y elaboración de resultados. XXVII Congreso Nacional de Riegos, León.

Merriam, J.L., Keller, J., 1978. Farm Irrigation System Evaluation: a Guide for Management. Utah St. Univ, Logan.

Wu, I.-P., Terry H, A., Hiler, E.A., 1979. Hydraulic design of drip irrigation systems.

Wu, I.P., Gitlin, H.M., 1975. Energy gradient line for drip irrigation laterals. J. Irrig. Drain. Div. 101 (4), 323-326.

Zhang, L., Wu, P., Zhu, D., 2013. Hydraulic design procedure for drip irrigation submain unit based on relative flow difference. Irrig. Sci. 31 (5), 1065-1073. https://doi.org/ 10.1007/s00271-012-0388-3. 